\title{
Information systems for smart services
}

\author{
Daniel Beverungen ${ }^{1} \cdot$ Martin Matzner $^{2} \cdot$ Christian Janiesch $^{3}$
}

Published online: 15 November 2017

(C) Springer-Verlag GmbH Germany 2017

\begin{abstract}
Digital interactions among businesses and consumers through powerful information systems and omnipresent connected devices establish today's networked society. In this light, Service Science continues to take root as a research discipline that focuses on the integration of (digital) resources by service providers and service customers for value co-creation in service systems. Rapid advances in information technology allow for designing novel information systems that enable entirely new configurations of service systems. In turn, Service Science also leaves its mark on the design, adoption, and use of information systems and technology. With this special issue, we compile a set of timely papers that investigate selected facets of the complex interplay between information technology, information systems, and Service Science to design innovative IT artifacts for smart service. This editorial opens this special issue by elaborating on our understanding of smart service.
\end{abstract}

Keywords Information system $\cdot$ Smart service $\cdot$ Service system

Daniel Beverungen

daniel.beverungen@uni-paderborn.de

Martin Matzner

martin.matzner@fau.de

Christian Janiesch

christian.janiesch@uni-wuerzburg.de

1 Paderborn University, Warburger Straße 100, 33098 Paderborn, Germany

2 Friedrich-Alexander-Universität Erlangen-Nürnberg, Lange Gasse 20, 90403 Nuremberg, Germany

3 Julius-Maximilians-Universität Würzburg, Josef-Stangl-Platz 2, 97080 Würzburg, Germany 


\section{Interplay of information systems and (smart) service systems}

We live in a world that is profoundly networked through digital technologies. In particular, the number of humans and devices that participate in the Cyberspace is growing tremendously. According to Statista Inc (2017), 1.86 billion people used smartphones in 2015; by 2020 , the number of smartphone users is estimated to reach 2.87 billion. The leading online social network Facebook reported having "over 2.01 billion monthly active Facebook users for June 2017", with " 1.15 billion mobile daily active users" for December 2016 (Zephoria Inc 2017). As reported by Forbes Media LLC (2017), the International Data Corporation (IDC) estimates that "by 2025 , approximately 80 billion devices will be connected to the Internet", while "approximately 11 billion devices connect to the Internet now". Likewise, IDC estimates that "by 2025 the total [amount of digital data created worldwide] will hit 180 zettabytes" ( 1 zettabyte $=1$ billion terabytes).

This unprecedented rise of digital technologies leads to the transformation of current business models and allows for the design of entirely new business models, many of which go by the names of smart $X$ scenarios. Examples of these scenarios include smart factory, smart home, smart logistics, smart energy, smart mobility, and smart health (Smart Service Welt Working Group and acatech 2015). They all have in common that technology is used to connect resources and actors with each other digitally for the sake of value co-creation. For instance, the enabling technology online social network allows consumers to network with other consumers digitally. The resulting network can interact with even other actors, including organizations such as businesses and government institutions.

In a trend that might turn out to be even more disruptive, smart devices or smart objects are increasingly equipped with sensors, data storage, data processing capabilities, and actuators, enabling them to join the digital world, as actors in their own right in an Internet of Things. Even home electronics now become equipped with information technology and enter the Internet as digital actors. For example, German home electronics manufacturer Miele has equipped more than 400 appliances-including washing machines, refrigerators, and cooker hoods-with digital technologies so that they can be part of the smart home (Miele \& Cie KG 2014).

While the ultimate objective of networking physical goods with information technology often is to create and capitalize on smart service as new or transformed value propositions that offer and provide value-in-use to customers, smart service also leaves its mark on different spheres of society. Capturing this zeitgeist as a Second Machine Age, Brynjolfsson and McAfee (2014) discuss several vast implications that digital transformation might have on the distribution of wealth and the transformation of workplaces and jobs.

Starting in 2012, the guest editors of this special issue have been hosting a conference track on Cyber-physical systems and digital value networks at the Multikonferenz Wirtschaftsinformatik (MKWI), which is a biannual conference of the German Information Systems community. For this track, we invite manuscripts that theorize on or design new IT artifacts for smart service. It was also at one of 
these conference tracks that we decided to edit this special issue, to summarize and highlight some current trends in the field, and to pave the way ahead for research on information systems for smart services.

\section{Conceptualizing digital service and smart service}

The term service system has been established as one of the core concepts of the Service Science discipline. It has first been introduced as a basic abstraction of the Service Science discipline by Spohrer et al. (2008) at the 41st Hawaii International Conference on Systems Sciences (HICSS 2008). A later incarnation of their paper defines the service system as a "configuration of people, technologies, and other resources that interact with other service systems to create mutual value" (Maglio et al. 2009, p. 395, emphasisadded). Importantly, this notion of a service system positions actors interacting with others for value co-creation center-stage. As digital technologies proliferate, scholarly publications increasingly use the term smart service. However, it is still open to debate what exactly makes service systems "smart" (and conversely, what exactly makes service systems "not smart").

The German National Academy of Science and Engineering (Acatech), emphasizing an outcome view on services, defines smart service as "individually configured bundles of products and services" (Smart Service Welt Working Group and acatech 2015, p. 4 ). An early and agenda-setting article by (Allmendinger and Lombreglia 2005, p. 131 f.) highlights in this regard that smart services "go beyond the kinds of upkeep and upgrades you may be bundling with your products, both in their value to customers and in their cost efficiency to you. To provide them, you must build intelligence-that is, awareness and connectivity-into the products themselves. And you must be prepared to act on what the products then reveal about their use". They further highlight the preemptive nature of smart service that is based on "hard field intelligence" on their status and surroundings that is identified and supplied by smart devices. Building on this notion, Töytäri et al. (2017) highlight the impact of smart service on interactions and business relationships between service providers and service customers.

The bottom line of the previous discussion is that products as digitally accessible objects or devices (or just "things") play an increasing role in service delivery. Summarizing a decade of research, Baines et al. (2007) conceptualize product service-systems (Becker et al. 2009) as both, the servicization of products and the productization of services. When applying information technology to these things, one can speak of smart devices (i.e., devices that exhibit physical and also digital properties). Smart devices can observe their environment through sensors or actuate through effectors while being able to communicate over a network and, thus, they can be active actors in a service system rather than just passive objects.

Departing from the notion of a service system, other authors have referred to smart service systems as socio-technical systems that amplify or augment "human capabilities to identify, to learn, to adapt, to monitor and to make decisions" (National Science Foundation 2016). Therefore, interpersonal elements and technology both need to be incorporated into smart service (Wünderlich et al. 
2012). Smart service systems exhibit digital and self-dependent characteristics. Barile and Polese (2010, p. 21) framed smart service systems as "service systems that are specifically designed for the prudent management of their assets and goals while being capable of self-reconfiguration to ensure that they continue to have the capacity to satisfy all the relevant participants over time". A recent National Science Foundation program's synopsis found that a smart service system's "capabilities are the result of the incorporation of technologies for sensing, actuation, coordination, communication, control, etc." (National Science Foundation 2016, p. 2). All the mentioned sources highlight (digital) interactions as one important characteristic of smart service systems. Smart service systems also refer to using smart devices as boundary objects to network resources and routinize interactions of the actors involved in a service system (Becker et al. 2013).

We conclude that information technology impacts service systems in two main directions. First, information technology makes people and things smart, allowing them to join the world as digital actors. Second, advanced information systems enable actors to interact digitally with other humans, with other devices, and with organizations, networking their resources and performing activities for value cocreation. Since the complexity of a system is a function of the number of elements in a system and the edges among them, it is clear that our current (and future) world will be increasingly complex, interconnected, and highly differentiated, allowing highly customized scenarios of value co-creation.

We coin service systems equipped with information technology digital service systems and, based on the notion of service (as introduced by Vargo and Lusch (2007, p. 16) and Lovelock and Gummesson (2004, p. 37)), we define digital service as follows:

A digital service is the application of digital "competencies through deeds, processes, and performances for the benefit of another entity or the entity itself" (see Vargo and Lusch 2007, p. 26). Digital competencies refer to digital assets and digital capabilities that one entity makes available to another entity through access or temporary possession. Also, digital service refers to making any asset or capability applicable to others using information technology, thereby enabling digital processes of value co-creation.

Based on this notion, we submit that smart service-referring to the smart $\mathrm{X}$ scenarios discussed above-go beyond this definition, since these scenarios are built on introducing smart devices into service systems. Based on properties such as awareness, connectivity, and actuation these smart devices extend the notion of digital service towards smart service.

A smart service is constituted by introducing smart devices into a digital service system. Smart devices network digital competencies of the actors involved in a digital service system and/or mediate their interactions. Smart devices display physical and digital features at the same time, such that they can observe, identify, and analyze physical and digital events, make decisions, and perform physical and/or digital actions. Therefore, a smart service 
integrates physical and digital competencies in a complex socio-technical service system.

Complementing these definitions, we coin service systems equipped with smart devices smart service systems.

Smart service and smart service systems offer many starting points for future research not only in the Information Systems discipline but also in neighboring fields. Benkenstein et al. (2017) identified the field of IT-driven services as a promising topic for further research, highlighting the digitization of services, process management of digital services, information systems for services, mobile devices for services, value co-creation in digital services, and big data in service industries. Janiesch et al. (2017) provide a manifesto that introduces 16 challenges from a technological angle, proposing how process management can improve the interaction of smart devices in an Internet of Things and how digital processes of value co-creation can benefit from better exploiting information available through smart devices. Wünderlich et al. (2015) highlight a need to investigate consumers' perceptions of embeddedness, analyze consumers' control of smart service, exploring consumers' co-creation of value, and developing new business models based on smart service.

Apart from these directions and based on our conceptualization of smart service, another particular issue that warrants further investigation is how value-in-use is cocreated by integrating physical and digital resources with each other at the same time.

\section{Structure of this issue}

In this special issue, we have compiled a set of three papers that investigate the complex interplay of smart service and information systems, and design new IT artifacts that can be used to develop, sell, and deliver smart service.

Dirk Metzger, Christina Niemöller, and Oliver Thomas propose a new approach for engineering what they call 'service technician support systems'. With their approach, they target value-added services for technical equipment in the engineering industries (smart factory). Since physical goods, services, and software increasingly converge to form integrated solutions, their approach is based on designing all three types of components in an integrated fashion. The approach, therefore, is envisioned to overcome the boundaries of several existing methods that focus on developing either of the components separately.

Antonia Albani, Yannic Domigall, and Robert Winter investigate customer value perceptions on smart metering services in Switzerland (smart energy). Based on a conjoint analysis with more than 1500 respondents, they identity five customer segments, four of which comprise customers who are willing to pay for smart metering services and also are willing to change their energy consumption behavior. Based on these results, the authors discuss implications for the design of a smart meter-based energy efficiency service. 
Guo Chao Peng, Miguel Baptista Nunes, and Luqing Zheng explore the adoption of a smart parking service in the city of London (smart mobility). In a survey of 212 local drivers and 470 online customers of the service, they estimate the business potential that can be realized with the service, including reduced $\mathrm{CO}_{2}$ emissions and cost savings. However, current benefits fall behind the business benefits and societal benefits expected from these data. Starting from this gap, the authors discuss means that would lead to a better exploitation of the expected potential.

The papers published in this special issue deal with concrete business cases for smart service, including smart factories, smart energy, and smart mobility. We hope that our initiative will be another starting point stimulating further research on the interplay of information systems and (smart) service systems.

With further special issues on smart service pending in other journals, including Electronic Markets and the Information Systems Journal, we are looking forward to the upcoming academic debate. Furthermore, in the spirit of smart service systems we encourage researchers to foster convergence between the disciplines involved in Service Science, including Computer Science, Information Systems, Marketing, and Mechanical Engineering.

\section{References}

Allmendinger G, Lombreglia R (2005) Four strategies for the age of smart services. Harv Bus Rev 83(10):131-145

Baines TS, Lightfoot HW, Evans S, Neely A, Greenough R, Peppard J, Roy R, Shehab E, Braganza A, Tiwari A et al (2007) State-of-the-art in product-service systems. In: Proceedings of the institution of mechanical engineers, Part B: Journal of Engineering Manufacture 221(10):1543-1552. doi:10. 1243/09544054jem858

Barile S, Polese F (2010) Smart service systems and viable service systems: applying systems theory to service science. Serv Sci 2(1-2):21-40. doi:10.1287/serv.2.1_2.21

Becker J, Beverungen DF, Knackstedt R (2009) The challenge of conceptual modeling for productservice systems: status-quo and perspectives for reference models and modeling languages. Inf Syst e-Business Manag 8(1):33-66. doi:10.1007/s10257-008-0108-y

Becker J, Beverungen D, Knackstedt R, Matzner M, Müller O, Poppelbuss J (2013) Bridging the gap between manufacturing and service through IT-based boundary objects. IEEE Trans Eng Manag 60(3):468-482. doi:10.1109/tem.2012.2214770

Benkenstein M, Bruhn M, Büttgen M, Hipp C, Matzner M, Nerdinger FW (2017) Topics for service management research—a european perspective. SMR J Serv Manag Res 1(1):4-21. doi:10.15358/ 2511-8676-2017-1-4

Brynjolfsson E, McAfee A (2014) The second machine age: work, progress, and prosperity in a time of brilliant technologies. W.W. Norton \& Company, New York City, NY

Forbes Media LLC (2017) 152,000 smart devices every minute in 2025. https://www.forbes.com/sites/ michaelkanellos/2016/03/03/152000-smart-devices-every-minute-in-2025-idc-outlines-the-futureof-smart-things/\#7f4ccffa4b63. Accessed 30 Sept 2017

Janiesch C, Koschmider A, Mecella M, Weber B, Burattin A, Ciccio CD, Gal A, Kannengiesser U, Mannhardt F, Mendling J, Oberweis A, Reichert M, Rinderle-Ma S, Song W, Su J, Torres V, Weidlich M, Weske M, Zhang L (2017) The internet-of-things meets business process management: mutual benefits and challenges. arXiv:1709.03628

Lovelock C, Gummesson E (2004) Whither services marketing? J Serv Res 7(1):20-41. doi:10.1177/ 1094670504266131

Maglio PP, Vargo SL, Caswell N, Spohrer J (2009) The service system is the basic abstraction of service science. Inf Syst e-Business Manag 7(4):395-406. doi:10.1007/s10257-008-0105-1 
Miele \& Cie KG (2014) 'smart home': Miele consolidates and expands its leading position. https://www. miele.de/en/m/smart-home-miele-consolidates-and-expands-its-leading-position-2422.htm. Accessed 30 Sept 2017

National Science Foundation (2016) Partnerships for innovation: Building innovation capacity. https:// www.nsf.gov/pubs/2016/nsf16591/nsf16591.pdf. Accessed 30 Sept 2017

Smart Service Welt Working Group, acatech (2015) Smart service welt-recommendations for the strategic initiative web-based services for businesses. Final Report, Berlin, Germany

Spohrer J, Vargo SL, Caswell N, Maglio PP (2008) The service system is the basic abstraction of service science. In: Proceedings of the 41st annual Hawaii international conference on system sciences (HICSS 2008) doi:10.1109/hicss.2008.451

Statista Inc (2017) Number of smartphone users worldwide from 2014 to 2020 (in billions). https:// zephoria.com/top-15-valuable-facebook-statistics/. Accessed 30 Sept 2017

Töytäri P, Turunen T, Klein M, Eloranta V, Biehl S, Rajala R, Hakanen E (2017) Overcoming institutional and capability barriers to smart services. In: Proceedings of the 50th Hawaii international conference on system sciences (2017) doi:10.24251/hicss.2017.198

Vargo SL, Lusch RF (2007) Why "service”? J Acad Mark Sci 36(1):25-38. doi:10.1007/s11747-0070068-7

Wünderlich NV, Fv Wangenheim, Bitner MJ (2012) High tech and high touch. J Serv Res 16(1):3-20. doi:10.1177/1094670512448413

Wünderlich NV, Heinonen K, Ostrom AL, Patricio L, Sousa R, Voss C, Lemmink JG (2015) "Futurizing" smart service: implications for service researchers and managers. J Serv Mark 29(6/ 7):442-447. doi:10.1108/jsm-01-2015-0040

Zephoria Inc (2017) The top 20 valuable facebook statistics—updated september 2017. https://zephoria. com/top-15-valuable-facebook-statistics/. Accessed 30 Sept 2017 